\title{
Cardiac resynchronization therapy in the elderly. How much is it safe and beneficial?
}

\author{
Francesco Vetta, Giampaolo Vetta, Sonia Bracchitta, Maria Mignano, Antonella Mattatelli \\ Cardiology Department, Israelitico Hospital, Rome, Italy
}

\begin{abstract}
Heart failure is a widespread disease in the western world whose incidence and prevalence are constantly increasing, mainly involving the more advanced age groups. Cardiac resynchronization therapy (CRT) has been shown able to reduce sudden cardiac death and all-cause mortality in patients with heart failure and reduced ejection fraction. Elderly patients are generally under-represented in the clinical trials aimed to evaluate the efficacy of CRT and, chiefly, of implantable cardiac defibrillator (ICD). The simultaneous presence of confounding factors such as co-morbidities, polypharmacy, changes in cognitive status, frailty, are the most important causes for the exclusion of subjects of advanced age from RCTs on the ICD or CRT implant. Current guidelines do not suggest any upper age limit for ICD and CRT but recommend avoiding their use in frail older patients with a life expectancy of less than 1 year. Data from the literature show that CRT has equal dignity in both the elderly and the young, in fostering effective functional and morphological improvements, also suggesting that, in older patients, CRT-D may have little practical value compared to CRT-P given the low incidence of arrhythmic death. Nevertheless, it is necessary to develop RCTs that consider aspects of the elderly patient in relation to CRT such as functional, cognitive and nutritional status.
\end{abstract}

Correspondence: Francesco Vetta, Cardiology Department, Israelitico Hospital, Via Fulda 14, 00148 Rome, Italy.

Tel. +39.06.65589369 - Fax +39.06.65589385.

E-mail: vettaaritmologia@gmail.com

Key words: Systolic heart failure; aging; cardiac resynchronization therapy.

Received for publication: 3 January 2019.

Accepted for publication: 28 January 2019.

(C) Copyright F. Vetta et al., 2019

Licensee PAGEPress, Italy

Monaldi Archives for Chest Disease 2019; 89:1025

doi: 10.4081/monaldi.2019.1025

This article is distributed under the terms of the Creative Commons Attribution Noncommercial License (by-nc 4.0) which permits any noncommercial use, distribution, and reproduction in any medium, provided the original author(s) and source are credited.

\section{Introduction}

In recent decades we are witnessing a progressive increase in the incidence and prevalence of heart failure (HF), due both to the improvement of therapies and technologies in use to counteract acute cardiovascular accidents, and to the progressive aging of the population. HF affects $1-2 \%$ of the general population in developed countries, with a prevalence rising to $10 \%$ among people aged 65 years or older. The average age at diagnosis has progressively increased over the years, up to the current age of 76 . Heart failure is the most common cause of hospitalization among the elderly and a common cause of re-admission to hospital resulting in financial burdens $[1,2]$. Given that the population over 65 years of age is exponentially increasing over the years, and chiefly very old people (over 85 years of age) heart failure has assumed the role of the most important cardiogeriatric syndrome and is rightly defined as the pandemic of the third millennium. Nevertheless, literature data on elderly subjects with heart failure are rather poor, as they are generally excluded in targeted clinical trials, due to the presence of confounding factors, such as comorbidities and polypharmacotherapy [3].

\section{Efficacy of cardiac resynchronization therapy in the elderly}

Cardiac resynchronization therapy (CRT), used in heart failure patients with advanced NYHA functional class despite an optimal medical therapy and with a wide QRS complex, improves ventricular function and, consequently, symptoms of heart failure, quality of life and exercise capacity, favoring, at the same time, a reduction in mortality and morbidity [4]. CRT has been shown to reduce mortality also in patients not receiving an ICD. Currently, the guidelines discourage the use of age as the sole assessment criterion for the implantation. The proportion of CRT devices increases with age, from $15 \%$ among patients aged 18-39 years to $40 \%$ among those over age 80 . It is unclear whether the beneficial effects of CRTs also apply to the elderly, as these patients have not been included in almost all randomized trials, mainly because of the coexistence of multiple co-morbidities, which, as is known, are typical of old age. In studies of CRT for severe HF, the median age of patients was $<70$ years [5]. Subgroup analysis of the Comparison of Medical Therapy, Pacing and Defibrillation in Heart Failure (COMPANION) and the Cardiac Resynchronization - Heart Failure (CARE-HF) revealed a benefit in terms of death and hospitalization in subjects aged $\geq 65$ years with use of CRT with ICD (CRT-D) compared to CRT with pacemaker (CRT-P), as well as a benefit of the latter compared to optimized medical ther- 
apy $[6,7]$.The results of the Multicenter Automatic Defibrillator Implantation Trial-Cardiac Resynchronization Therapy (MADITCRT), according to previous data, have shown that CRT-D has significantly reduced the composite end point of death and heart failure among subjects aged between 60 and 74 years and in subjects older than 75 years, while this reduction was not significant in subjects aged $<60$ years $[8,9]$.

As regards the effect of CRT in the elderly on reverse remodeling and improvement of left ventricular systolic function (LVEF), an analysis of randomly assigned patients in the MIRACLE and MIRACLE-ICD studies showed no age-related differences in improvement of LVEF in age subclasses (less than 65 years, 65-75 years and over 75 years) [10]. Killu, in a study comparing CRT in subjects $>80$ years of age to subjects with an average age of about 66 years, observed a significant improvement in HF symptoms, left ventricular systolic function and reverse LV remodeling in subjects over 80 years of age with severe heart failure, comparable to younger patients [11].

\section{Safety of cardiac resynchronization therapy in the elderly}

Although there is a series of publications describing the clinical outcome of CRT in elderly subjects, data on periprocedural complications are surprisingly scarce. In fact, although there are more than 3500 scientific publications focusing on CRT / ICD implantation in patients $>65$ years, only about twenty are those analyzing implant safety in patients $>75$ years. Finally, most of the latter have not analyzed periprocedural complications during the implantation of the device [12]. Therefore, only five retrospective studies are available for the safety assessment of procedures (Table 1). In four studies, the authors used the age limit of 80 years to define the elderly population, while in one of them the limit was lowered to 75 years. In each of these studies, there was no statistically significant difference in total adverse event rates between older and younger subjects. Only the Olechowski study showed a significant difference in the number of pneumothoraxes between older and younger patient groups. These data, therefore, focus on the various techniques proposed to minimize the risk of pneumothorax during venous access for the implantation of CRT devices, as well as for pacemakers [13]. The use of ultrasound support for the detection and puncture of the subclavian vein and the use of the cephalic vein as the only access for all leads, are currently the most accepted and safe techniques. Systematic use of cephalic access for as many leads as possible should be the main route for all electrophysiologists [14].

Therefore, the few data in the literature on this issue do not highlight significant age-related differences in procedural and periprocedural safety of CRT implantation, although it should be noted that the literature data consider obsolete clinical parameters, which do not adequately reflect the clinical characteristics of the frail elderly patient [3].

\section{CRT-D or CRT-P in the elderly?}

Recent studies have shown that patients aged 75 years and older represent more than $50 \%$ of patients with heart failure. Current guidelines do not suggest any upper age limit for ICD or CRT implantation but recommend avoiding of implantation of these devices in frail elderly subjects with a life expectancy of less than one year. A recent meta-analysis has shown that among subjects undergoing CRT device implantation, age is an important discriminating factor. In fact, while in subjects over 75 years only a third of them were implanted with CRT-D, this percentage has almost doubled in younger subjects [15]. This difference is widely justified in the literature. A recent study focused on the mode of death of almost 180 patients over the age of 80 with a mean follow-up of 38 months. The ultra-octogenarian cohort, equally divided between ischemic and non-ischemic substrates, included $21 \%$ of CRT-D receiving patients, and was predominantly in class II (31\%) and III (64\%) of the New York Heart Association (NYHA), with left bundle branch block (78\%). The Authors, at the intermediate six months follow up, noted similar improvements in left ventricular size, left ventricular ejection fraction and NYHA class in ultra-octogenarians and in younger patients. Mode of death was ascertained in 100 patients mainly from electronic medical records. Deaths among ultra-octogenarians were largely non-cardiac (74\% vs $50 \%$ among younger patients) and only one (3\%) was tachyarrhythmic, compared to $11 \%$ of tachyarrhythmic deaths in younger patients [16]. The increasing prevalence of comorbidities and geriatric syndromes, such as dementia, incontinence, falls and frailty, is one of the hallmarks of elderly patients. It has been estimated that more than $66 \%$ of patients with heart failure have two or more non-cardiac comorbidities and more than $25 \%$ may have six or more concomitant diseases. These data clearly show that HF in elderly people is never an isolated condition, contrary to what can be seen in middle-aged patients and treatment should be stud-

Table 1. Safety of CRT implantation in older and younger patients. Modified from Mikhaylov and Lebedev, J Geriatr Cardiol 2016;13:277-8 [19].

\begin{tabular}{|c|c|c|c|c|c|c|c|c|c|}
\hline Author & $\begin{array}{l}\text { Age cut-off } \\
\text { (years) }\end{array}$ & $\begin{array}{l}\text { Number of } \\
\text { younger } \\
\text { patients }\end{array}$ & $\begin{array}{c}\text { Number of } \\
\text { older } \\
\text { patients }\end{array}$ & $\begin{array}{l}\text { Total early } \\
\text { complications } \\
\text { in younger } \\
\text { patients }\end{array}$ & $\begin{array}{l}\text { Total early } \\
\text { complications } \\
\text { in older } \\
\text { patients }\end{array}$ & $\mathbf{P}$ & $\begin{array}{c}\text { Pneumothorax } \\
\text { in younger } \\
\text { patients }\end{array}$ & $\begin{array}{l}\text { Pneumothorax } \\
\text { in older } \\
\text { patients }\end{array}$ & $\mathbf{P}$ \\
\hline Achilli, 2007 [17] & 80 & 1096 & 85 & $48(4.4 \%)$ & $2(2.4 \%)$ & NS & 0 & 0 & NS \\
\hline Verbrugge, 2013 [20] & 80 & 171 & 49 & $66(3.5 \%)$ & 0 & NS & $1(0.6 \%)$ & 0 & NS \\
\hline Killu, 2013 [11] & 80 & 638 & 90 & $85(13.3 \%)$ & $13(14.4 \%)$ & NS & $8(1.3 \%)$ & $2(2.2 \%)$ & NS \\
\hline Höke, 2014 [21] & 75 & 590 & 208 & $31(5.2 \%)$ & $12(5.8 \%)$ & NS & $3(0.5 \%)$ & $2(1.4 \%)$ & NS \\
\hline Olechowski, 2015 [13] & 80 & 324 & 115 & $55(17 \%)$ & $18(16 \%)$ & NS & $4(1.2 \%)$ & $5(4.3 \%)$ & $<0.05$ \\
\hline Total (all studies) & Both 75 and 80 & 2819 & 547 & $284(10.11 \%)$ & $45(8.23 \%)$ & NS & $16(0.57 \%)$ & $9(1.65 \%)$ & 0.027 \\
\hline
\end{tabular}

NS, not significant. 
ied taking into account the coexistence of numerous comorbidities. Among the latter, the most common include renal dysfunction, anemia, chronic lung disease, depression, arthritis, sensory and nutritional disorders [3]. Given their reduced life expectancy and increased competing risk of non-cardiac death, the decision to implant an ICD in the elderly remains controversial. Recent scientific evidence suggests that patients with ischemic cardiomyopathy are more likely to benefit from ICD implantation than those with non-ischemic cardiomyopathy. Despite the higher prevalence of ischemic cardiomyopathy in the elderly, they are less likely to receive an ICD. This paradox suggests a potential gap in the care of elderly patients with HF. Considering that the additional risk of implanting an ICD is low in elderly patients undergoing de novo CRT implantation and that their life expectancy should be at least 1 year, the infrequent use of ICDs in these patients may be partially justified by additional costs and poor representation of these patients in randomized controlled trials. Age alone is judged insufficient to aid the decision to implant the ICD [17]. Appropriate patient selection is essential to identify elderly patients who are more likely to benefit from the reduction of sudden cardiac death by an ICD. Ideal elderly patients who would benefit from ICD are certainly those at low risk of non-cardiac death. Several risk scores have been proposed to identify predictors of mortality after ICD implantation $[18,19]$. These include old age, atrial fibrillation, liver failure and renal function, symptomatic heart failure and depressed LVEF. A balanced analysis of these factors is crucial to the search for patients whose risk of non-cardiac death (as well as of non-sudden cardiac death) is relatively low. However, it is essential to consider more specific aspects of the elderly patient, such as functional status, cognitive-affective status, and nutritional status. In this context, specific data derived from targeted RCTs are needed to highlight this.

\section{References}

1. Díez-Villanueva P, Alfonso F. Heart failure in the elderly. J Geriatr Cardiol 2016;13:115-7.

2. Lazzarini V, Mentz RJ, Fiuzat M, et al. Heart failure in elderly patients: distinctive features and unresolved issues. Eur J Heart Fail 2013;15:717-3.

3. Kramer DB, Reynolds MR, Mitchell SL. Resynchronization: considering device-based cardiac therapy in older adults. J Am Geriatr Soc 2013;61:615-21.

4. Normand C, Linde C, Singh J, Dickstein K. Indications for cardiac resynchronization therapy: A comparison of the major international guidelines. JACC Heart Fail 2018;6:308-16.

5. Antonio N, Lourenco C, Teixeira R, et al. Cardiac resynchronization therapy is effective even in elderly patients with comorbidities. J Interv Card Electrophysiol 2010; 27:61-8.

6. Bristow MR, Saxon LA, Boehmer J, et al. Cardiac-resyn- chronization therapy with or without an implantable defibrillator in advanced chronic heart failure. N Engl J Med 2004; 350:2140-50.

7. Cleland JGF, Daubert JC, Erdmann E et al. The Effect of Cardiac Resynchronization on Morbidity and Mortality in Heart Failure. N Engl J Med 2005; 352:1539-1549.

8. Bleeker GB, Schalij MJ, Molhoek SG, et al. A comparison of effectiveness of cardiac resynchronization therapy in patients $<70$ versus $\geq 70$ years of age. Am J Cardiol 2005;96:420-2.

9. Penn J, Goldenberg I, Mossa AJ et al. Improved outcome with preventive cardiac resynchronization therapy in the elderly: A MADIT-CRT Substudy. J Cardiovasc Electrophysiol 2011:22: 892-97.

10. Kron J, Aranda JM Jr, Miles WM, et al. Benefit of cardiac resynchronization in elderly patients: results from the Multicenter InSync Randomized Clinical Evaluation (MIRACLE) and Multicenter InSync ICD Randomized Clinical Evaluation (MIRACLE-ICD) trials. J Interv Card Electrophysiol 2009;25:91-6.

11. Killu AM, Wu J, Friedman PA, et al. Outcomes of cardiac resynchronization therapy in the elderly. Pacing Clin Electrophysiol 2013;36:664-72.

12. Barra S, Providencia R, Paiva L, et al. Implantable cardioverter-defibrillators in the elderly: rationale and specific age-related considerations. Europace 2015;17:174-86.

13. Olechowski B, Sands R, Zachariah D, et al. Is cardiac resynchronisation therapy feasible, safe and beneficial in the very elderly? J Geriatr Cardiol 2015;12:497-501.

14. Swindle JP, Rich MW, McCann P, et al. Implantable cardiac device procedures in older patients: Use and in-hospital outcomes. Arch Intern Med 2010;170:631-7.

15. Chugh SS, Aro AL, Reinier K. The conundrum of defibrillators in the elderly. J Am Coll Cardiol 2017;69:275-7.

16. Martens P, Verbrugge FH, Nijst P, et al. Mode of death in octogenarians treated with cardiac resynchronization therapy. J Card Fail 2016;22:970-7.

17. Achilli A, Turreni F, Gasparini M, et al. Efficacy of cardiac resynchronization therapy in very old patients: the Insync/Insync ICD Italian Registry. Europace 2007;9:732-8.

18. Parkash R, Stevenson WG, Epstein LM, Maisel WH. Predicting early mortality after implantable defibrillator implantation: a clinical risk score for optimal patient selection. Am Heart J 2006;151:397-403.

19. Mikhaylov EN, Lebedev DS. Cardiac resynchronization in the elderly is beneficial, but could we implant our devices in old patients safer? J Geriatr Cardiol 2016;13:277-8.

20. Verbrugge FH, Dupont M, De Vusser P, et al. Response to cardiac resynchronization therapy in elderly patients ( $\geq 70$ years) and octogenarians. Eur J Heart Fail 2013;15:203-10.

21. Höke U, Putter H, Van Der Velde ET, et al. Left ventricular reverse remodeling, device-related adverse events, and longterm outcome after cardiac resynchronization therapy in the elderly. Circ Cardiovasc Qual Outcomes 2014;7:437-44. 